University of Nebraska - Lincoln

DigitalCommons@University of Nebraska - Lincoln

\title{
Evaluation of protection in a mouse model after vaccination with Mycobacterium avium subsp. paratuberculois protein cocktails
}

\author{
J.R. Stabel \\ USDA-ARS, National Animal Disease Center, judy.stabel@ars.usda.gov
}

A. Barnhill

USDA-ARS, National Animal Disease Center

J. P. Bannantine

USDA-ARS, National Animal Disease Center, john.bannantine@usda.gov

Y.F. Chang

Cornell University, Ithaca

M.A. Osman

lowa State University, Ames

Follow this and additional works at: https://digitalcommons.unl.edu/usdaarsfacpub

Part of the Agriculture Commons

Stabel, J.R.; Barnhill, A.; Bannantine, J. P.; Chang, Y.F.; and Osman, M.A., "Evaluation of protection in a mouse model after vaccination with Mycobacterium avium subsp. paratuberculois protein cocktails" (2012). Publications from USDA-ARS / UNL Faculty. 2445.

https://digitalcommons.unl.edu/usdaarsfacpub/2445

This Article is brought to you for free and open access by the U.S. Department of Agriculture: Agricultural Research Service, Lincoln, Nebraska at DigitalCommons@University of Nebraska - Lincoln. It has been accepted for inclusion in Publications from USDA-ARS / UNL Faculty by an authorized administrator of DigitalCommons@University of Nebraska - Lincoln. 


\title{
Evaluation of protection in a mouse model after vaccination with Mycobacterium avium subsp. paratuberculois protein cocktails
}

\author{
J.R. Stabel ${ }^{\mathrm{a}, *}$, A. Barnhill ${ }^{\mathrm{a}}$, J.P. Bannantine ${ }^{\mathrm{a}}$, Y.F. Chang ${ }^{\mathrm{b}}$, M.A. Osman ${ }^{\mathrm{c}}$ \\ a USDA-ARS, National Animal Disease Center, Ames, IA 50010, USA \\ b Cornell University, Ithaca, NY 14850, USA \\ ${ }^{\mathrm{c}}$ Iowa State University, Ames, IA 50011, USA
}

\section{A R T I C L E I N F O}

\section{Article history:}

Received 1 August 2012

Received in revised form 16 October 2012

Accepted 25 October 2012

Available online 6 November 2012

\section{Keywords:}

Mycobacterium avium subsp.

paratuberculosis

Vaccine

Protein

Mice

\begin{abstract}
A B S T R A C T
Whole-cell vaccines successfully reduce signs of clinical disease and fecal shedding of Mycobacterium avium subsp. paratuberculosis (MAP), however, these vaccines have some limitations. The present study was conducted to identify MAP proteins that might be candidates for the development of an improved vaccine. MAP proteins were screened for immunogenicity in naturally infected cattle and selected based upon reactivity in the interferon- $\gamma$ (IFN- $\gamma$ ) and Western blot assays. Proteins (MAP1087, MAP1204, MAP1272c, and MAP2077c) were arrayed into 4 overlapping cocktails containing 3 proteins each. The efficacy of the proteins within these cocktails as vaccine candidates was evaluated by subcutaneous immunization of mice, followed by challenge with live, virulent MAP. All MAP protein cocktails significantly reduced the recovery of live MAP from the ileum, while cocktails 1 and 3 reduced colonization in the liver. No significant differences were seen in the mesenteric lymph node or spleen, however, cocktail 1 reduced viable MAP in the mesenteric lymph node compared to other treatments. Stimulation of splenocytes upregulated antigen-specific IFN- $\gamma$ and IL-23 secretion in all treatment groups, regardless of vaccination. Interestingly, IL-4 was moderately downregulated for vaccinates compared to control infected mice. An increase in total CD25 expression was noted for 3 of the 4 vaccinate groups upon stimulation of splenocytes with a whole cell sonicate of MAP, with this effect becoming more significant within CD4CD25+ and CD8CD25+ subpopulations. The present study demonstrated that MAP proteins are useful as vaccine candidates to reduce MAP tissue burden.
\end{abstract}

Published by Elsevier Ltd.

\section{Introduction}

Paratuberculosis vaccine studies have demonstrated the induction of both cellular and humoral immune responses, however, it is widely accepted that vaccination will not prevent infection. Some benefits of vaccination include reduced fecal shedding of MAP and reduced clinical signs in infected animals, with evidence suggesting a reduction in the incidence of disease within herds or severity of disease for individual animals [1-3]. The heat-killed whole cell vaccine that is approved for use in the US (Mycopar, Fort Dodge Animal Health) is not ideal because of potential adverse reactions, including severe inflammation and granuloma formation at the injection site. In addition, vaccination with whole cell vaccines has been shown to interfere with bovine tuberculosis skin testing and serologic detection of MAP infected animals [4-6]. Developing subunit or DNA vaccines would significantly reduce or eliminate some of

\footnotetext{
* Corresponding author at: USDA-ARS, National Animal Disease Center, 2300 Dayton Road, Ames, IA 50010, USA. Tel.: +1 515663 7304; fax: +1 5156637458 .

E-mail address: judy.stabel@ars.usda.gov (J.R. Stabel).
}

the troubling aspects of the whole cell vaccine without sacrificing beneficial properties.

Several MAP proteins or protein complexes have demonstrated success for use as subunit vaccines, including a $70 \mathrm{kDa}$ heat shock protein, a novel $74 \mathrm{~F}$ polyprotein, and a mixture of Ag85/SOD proteins. Immunization with these protein or protein complexes has provided protection against MAP challenge in mice, cattle and goat models, resulting in reduced colonization of tissues and decreased shedding in the feces [7-9]. Each of these subunit vaccines has demonstrated that they are able to induce both cell-mediated and humoral immune responses in the respective hosts, suggesting strong protective measures. Further, it was recently demonstrated that the Hsp70 subunit vaccine does not cross-react with the comparative cervical skin test, a diagnostic tool commonly used for bovine tuberculosis in the field [10]. Positive responses to AvPPD were noted in all vaccinated animals, however, responses to BoPPD were demonstrated only for cattle vaccinated with whole cell vaccine (Gudair) and not for those vaccinated with Hsp70 [10], demonstrating that a subunit vaccine can be more discriminative for identification of animals infected or vaccinated against MAP versus those animals infected with Mycobacterium bovis. 
Table 1

Mycobacterium avium subsp. paratuberculosis proteins.

\begin{tabular}{|c|c|c|c|c|c|}
\hline NCBI gene ID ${ }^{a}$ & Locus tag & Size (kDa) & Predicted function & M. avium homologb & Vaccine pools \\
\hline 2719512 & MAP1087 & 15.4 & ABC transporter permease & MAV_3420 & $1,2,3$ \\
\hline 2720812 & MAP1204 & 25.4 & Putative invasion protein; NipC/P60 family; cell wall-associated hydrolase & MAV_3300 & $1,2,4$ \\
\hline 2720835 & MAP1272c & 33.4 & Putative invasion protein; NipC/P60 family; cell wall-associated hydrolase & MAV_3208 & $1,3,4$ \\
\hline 2719950 & MAP2077c & 11.1 & STAS $^{\mathrm{c}}$ domain containing protein & MAV_2109 & $2,3,4$ \\
\hline
\end{tabular}

a A unique identification number for sequences in the NCBI database.

b The locus tag for the corresponding protein in M. avium subspecies hominissuis strain 104

c STAS is an acronym for sulfate transporter antagonist of anti-sigma factor.

Disadvantages of protein vaccines are that purified antigens often do not stimulate robust or durable immune responses, requiring adjuvants to enhance effectiveness. Adjuvants used in veterinary vaccines are often based upon fragments of mycobacteria and other bacteria or chemicals that elicit strong inflammatory responses to stimulate immunity [11]. The use of adjuvants with protein-based vaccines can reduce the amount of antigen needed, as well the number of immunizations required to achieve protective immunity. In the present study, cocktails of MAP proteins previously shown to elicit strong immune responses in cattle were evaluated for host immunity and potential use as vaccine candidates for protection against MAP infection in a mouse model.

\section{Materials and methods}

\subsection{Antigen screening}

Four MAP proteins were evaluated for reactivity with control noninfected, subclinically and clinically infected cattle in a whole blood interferon- $\gamma($ IFN- $\gamma$ ) assay. Infection status of cattle was confirmed by bacteriologic culture for the fecal shedding of MAP and serologic assays by standard methods $[12,13]$. Whole blood was incubated with medium only (nonstimulated; NS), concanavalinA (ConA, Sigma), pokeweed mitogen (PWM; $10 \mu \mathrm{g} / \mathrm{ml}$; Sigma), johnin purified protein derivative (JPPD; $10 \mu \mathrm{g} / \mathrm{ml}$; National Veterinary Services Laboratory, Ames, IA), a whole-cell sonicate of MAP (MPS; $10 \mu \mathrm{g} / \mathrm{ml}$; NADC), and one of the following MAP proteins, MAP1087, MAP1204, MAP1272c, MAP2077c, (Table 1; $10 \mu \mathrm{g} / \mathrm{ml}$ ). After incubation at $39^{\circ} \mathrm{C}$ for $18 \mathrm{~h}$, plasma was assayed using a Bovigam IFN- $\gamma$ assay (Prionics, La Vista, NE). The selection of the 4 MAP proteins, MAP1087, MAP1204, MAP1272c, and MAP2077c, used in the present study was based upon their immunogenic potential as defined by robust antigen-specific IFN- $\gamma$ and antibody responses in infected cattle and negligible responses in noninfected control cows. These 4 proteins were arrayed in 4 cocktails containing 3 of the 4 proteins as follows: cocktail 1: MAP1087, MAP1204, MAP1272c; cocktail 2: MAP1087, MAP1204, MAP2077c; cocktail 3: MAP 1087, 1272c, 2077c; and cocktail 4: MAP1204, MAP1272c, 2077c.

\subsection{Protein expression and purification}

The four annotated coding sequences of the proteins were selected from a battery of recombinant proteins amplified from strain K-10 genomic DNA. The methods for expression and purification of MAP recombinant proteins are described in detail [14]. 74F polyprotein, consisting of a combination of MAP1519 and MAP3527 peptides, was constructed as previously described [8]. The $74 \mathrm{~F}$ polyprotein had previously demonstrated efficacy in the mouse model as a vaccine for paratuberculosis [8].

\subsection{Bacterial strain}

MAP used as the challenge strain was isolated from the ileum of clinical cow 167 (NADC) and was grown in Middlebrook 7H9 liquid medium (pH 5.9) supplemented with $0.5 \%$ Tween 80 (Sigma), $2 \mathrm{mg} / \mathrm{ml}$ mycobactin J (Allied Monitor Inc., Fayette, MO) and 10\% oleic acid-albumin-dextrose complex (BD Biosciences, Franklin Lakes, NJ). The final concentration of the bacteria was adjusted to $10^{9} \mathrm{cfu} / \mathrm{ml}$ and confirmed by serial dilution onto agar slants of Herrold's egg yolk medium (HEYM; BD) containing $2 \mathrm{mg} / \mathrm{l}$ of mycobactin J(Allied Monitor) with a final read-out after 12 weeks of incubation. The presence of each of the 4 MAP proteins in the cocktails was confirmed in this strain by PCR and Western blot (data not shown). Clinical cow strain 167 was used as the challenge strain as it was expanded from a primary isolate from ileal tissue of a highly infected cow and had not been subjected to repeated passage in laboratory medium.

\subsection{Mice}

Six-week old, male Balb/c mice used in the study (Jackson Labs, Bar Harbor, Maine) were housed in biosecurity level-2 containment in disposable plastic cages with free access to water and standard mouse chow. All procedures were approved by the NADC Animal Care and Use Committee.

\subsection{MAP vaccines}

Mice were randomly assigned to 7 treatment groups containing 10 mice each as follows: control uninfected (no vaccine, no MAP), control infected (no vaccine, MAP infection), 74F protein only (74F vaccine, MAP infection), cocktail 1 (cocktail 1, MAP infection), cocktail 2 (cocktail 2, MAP infection), cocktail 3 (cocktail 3, MAP infection) and cocktail 4 (cocktail 4, MAP infection). The 74F group received $50 \mu \mathrm{g}$ total protein as described in a previous study [8] and mice in cocktail 1-4 groups were given $100 \mu \mathrm{g}$ total protein in $100 \mu$ l volume per mouse subcutaneously (SQ) in the dorsal region. The control uninfected and control infected groups received $100 \mu \mathrm{l}$ PBS as sham injections. Mice within each treatment group were boosted with the identical vaccine 3 weeks after the initial immunization. Two weeks after boosting, mice were inoculated intraperitoneally with live, virulent MAP strain $167\left(10^{8}\right.$ in $\left.100 \mu \mathrm{l}\right)$. Three months after infection, mice were anesthetized by inhalation of isoflurane and decapitated with a guillotine. The liver, spleen, ileum and mesenteric lymph node were removed from each mouse, weighed, and processed for tissue culture as previously described [15]. Splenocytes were isolated from a portion of the spleen and cultured at $2.0 \times 10^{6}$ cells $/ \mathrm{ml}$ with medium only (NS); ConA, $10 \mu \mathrm{g} / \mathrm{ml}$; PWM, $10 \mu \mathrm{g} / \mathrm{ml}$; and MPS, $10 \mu \mathrm{g} / \mathrm{ml}$. Quantitative cytokine analyses was performed on $24 \mathrm{~h}$ supernatants for interleukins (IL)-2, IL-4, IL-10, IL-12, IL-23 and IFN- $\gamma$ using commercial ELISA kits, according to accompanying protocol (R \& D Systems, Minneapolis, MN). After 6 days of incubation, splenocytes were harvested for flow cytometric analyses of CD3, CD4, $\gamma \delta$ T cells (BD Biosciences), CD8, B cells, monocytes, CD44, CD62L, and CD25 expression (BioLegend, San Diego, CA). Data analyses were performed using FlowJo software (TreeStar, Inc., San Carlos, CA).

Antigen-specific $\operatorname{IgG}_{1}$ and $\operatorname{IgG}_{2 a}$ responses were measured in mouse sera by ELISA. Briefly, plates (Nunc MaxiSorp module, Nunc, 


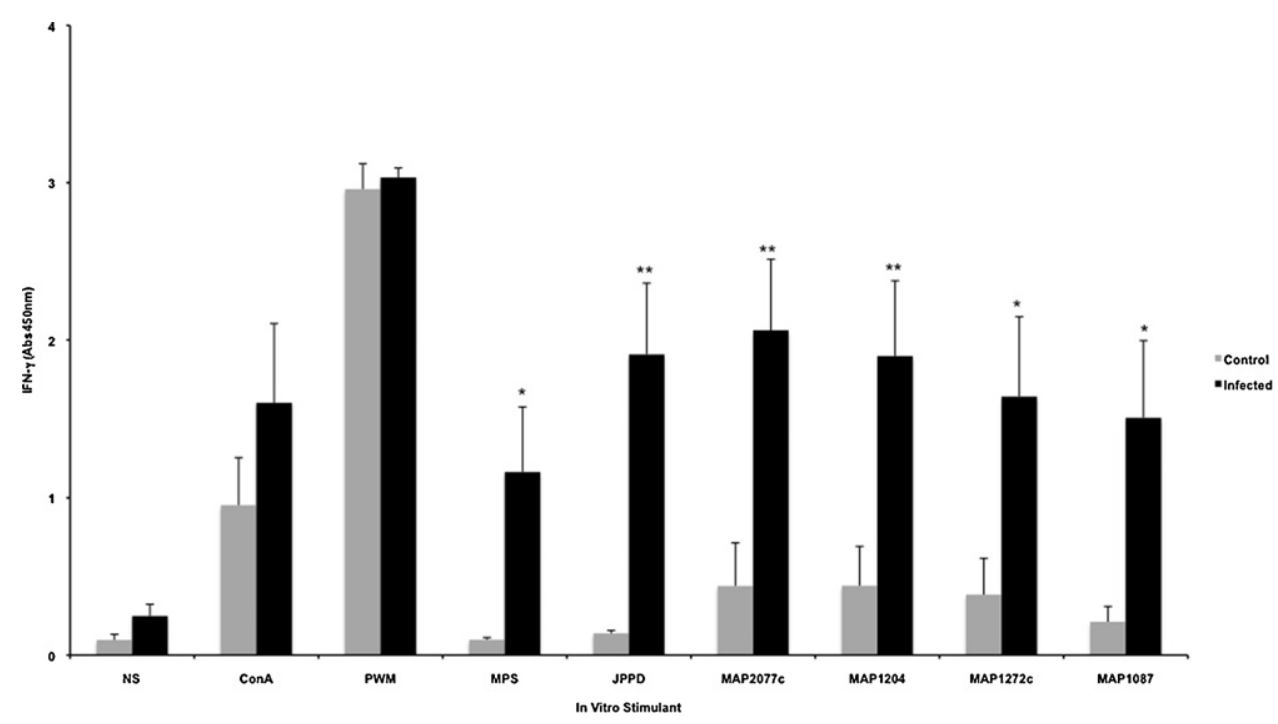

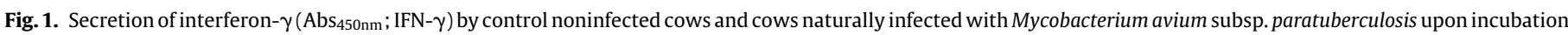

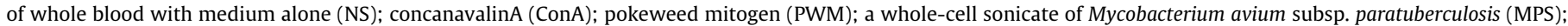

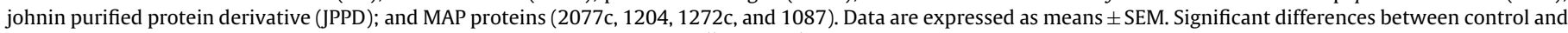
infection cows within in vitro treatment group are represented by asterisks $\left({ }^{* *} P<0.01 ;{ }^{*} P<0.05\right)$.

Roskilde, Denmark) were coated with $200 \mathrm{ng} /$ well of a whole cell sonicate preparation of MAP (clinical strain 167, NADC) and incubated at $4{ }^{\circ} \mathrm{C}$ overnight. After blocking ( $1 \% \mathrm{BSA}$ in TBST), diluted sera were added to the wells and incubated at $25^{\circ} \mathrm{C}$ for $1 \mathrm{~h}$, followed by incubation with either horseradish peroxidase-conjugated goat anti-mouse $\operatorname{IgG}_{1}$ or $\operatorname{IgG}_{2 a}$ (Kamiya Biochemical Co., Seattle, WA) for $20 \mathrm{~min}$, and 3,3',5,5'-tetramethylbenzidine substrate solution (TMB; Kamiya Biomedical Co.) for $10 \mathrm{~min}$. Absorbance at $450 \mathrm{~nm}$ was measured in a Victor $\mathrm{X}_{3}$ Microplate reader (Perkin-Elmer, Shelton, CT).

\subsection{Statistical analysis}

Data were analyzed using PROC MIXED procedure of the Statistical Analysis System (SAS Inst., Inc., Cary, NC). The model included the fixed effects of treatment (vaccination), stimulation (in vitro treatment), and treatment $\times$ stimulation interaction. When significant effects $(P<0.05)$ due to treatment, stimulation, or treatment $\times$ stimulation interactions were detected, means separation was conducted by the Student's $t$-test option in SAS. Designation of statistical significance within figures is described in each figure legend. Broad measures of statistical significance due to treatment or treatment $\times$ stimulation interactions may only be denoted within the text of the manuscript.

\section{Results}

\subsection{Immunogenicity of MAP protein candidates}

The MAP proteins (MAP1087, MAP1204, MAP1272c, and MAP2077c) used in the present study to formulate vaccine cocktails demonstrated strong immunogenic potential, producing antigenspecific IFN- $\gamma$ responses similar to or greater than the whole-cell sonicate of MAP (MPS) in Johne's subclinical and clinical cows (Fig. 1).

\subsection{Cytokine results}

Results for Th1 and Th2-mediated cytokine secretion from splenocytes stimulated with either medium alone (NS) or with MPS are presented in Fig. 2. Stimulation of cells with MPS resulted in an upregulation $(P<0.05)$ of IFN- $\gamma$ compared to NS cultures in all infected groups. Vaccination with MAP protein cocktails reduced IFN- $\gamma$ responses to MPS overall when compared to the control infected and 74F treatment groups $(P<0.05)$. Secretion of IL-12 followed a similar trend with greater responses noted for the control infected and $74 \mathrm{~F}$ groups compared to the protein cocktail vaccinates (Fig. 2B). MPS-stimulated splenocytes had greater $(P<0.05)$ IL-4 responses compared to NS cultures only in control infected mice (Fig. 2C). Interestingly, immunization with MAP protein cocktails resulted in increased $(P<0.05)$ IL-4 secretion in NS cultures for mice immunized with cocktails 1 and 2 compared to control infected mice. There were no significant effects due to vaccination on the secretion of IL-10, regardless of in vitro stimulation, however $(P<0.05)$ differences between NS and MPS-stimulated cultures were observed for control infected mice (Fig. 2D). Secretion of IL-2 and IL-23 was not influenced by vaccination but an upregulation of IL-23 was observed by stimulation of splenocytes with MPS in all infected mice (data not shown).

\subsection{T cell populations}

Vaccination with protein cocktails $1-3$ and $74 \mathrm{~F}$ resulted in higher $(P<0.05)$ CD4T cells compared to control infected mice, regardless of in vitro treatment (data not shown). In addition, immunization of mice with MAP protein cocktails (1-3) or 74F resulted in dramatic $(P<0.05)$ upregulation of CD4CD25T cells in MPS-stimulated cultures compared to NS cultures (Fig. 3A and B). There were no major differences in CD8T cells due to vaccination of mice (data not shown), however, the number of CD8CD25T cells was significantly $(P<0.05)$ upregulated in MPS-stimulated splenocytes across treatment groups (Fig. $3 C$ and D). There were no differences in the percentage of $\gamma \delta$ T cells and $\gamma \delta C D 25+$ cells due to vaccination, yet there was a consistent trend toward reduced numbers of these cell types after MPS stimulation of splenocytes in all treatment groups (data not shown). There was a trend for increased total CD25T cells in mice vaccinated with MAP proteins or $74 \mathrm{~F}$ although only mice in cocktail 4 had significantly $(P<0.05)$ higher CD25T cells after MPS stimulation of splenocytes than control infected mice $(8.30 \pm 1.76$ versus $5.46 \pm 0.70$, respectively; data not shown). Total percentages of CD44, CD62L, and monocytes in 

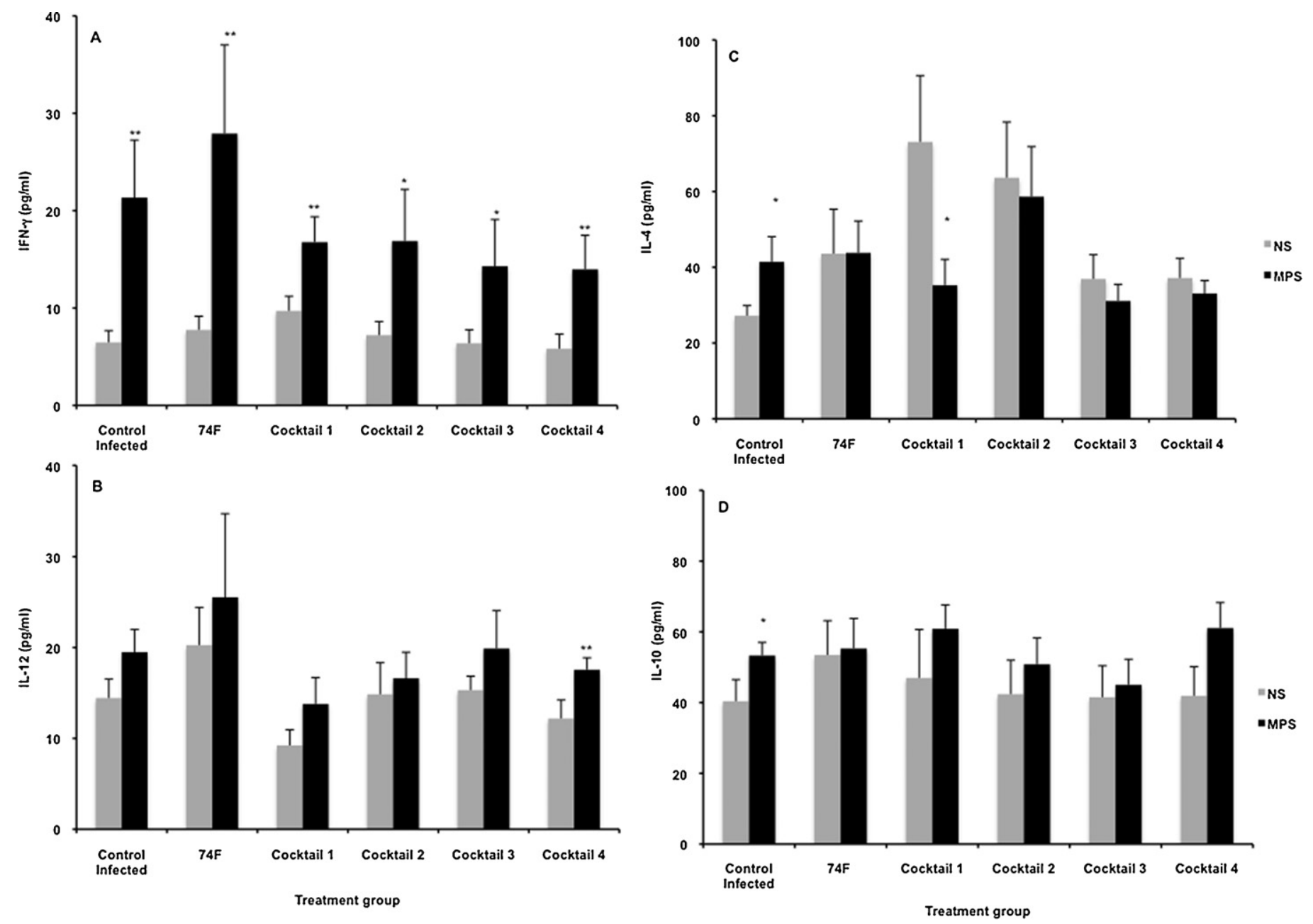

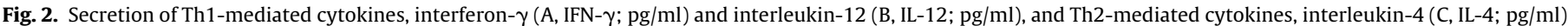

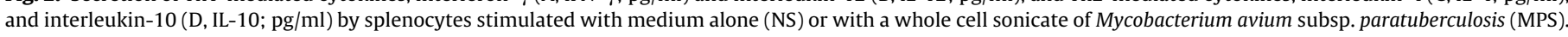

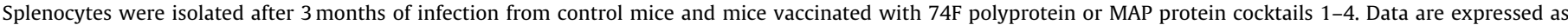
means \pm SEM. Significant differences between NS and MPS within treatment group are represented by asterisks $\left({ }^{* *} P<0.01 ;{ }^{*} P<0.05\right)$.

splenocyte cultures were unaffected by immunization of mice or in vitro treatment in the present study (data not shown).

\subsection{B cells and MAP-specific serum $\operatorname{Ig} G_{1}$ and $\operatorname{Ig} G_{2 a}$ results}

Interestingly, the percentages of B cells within MPS-stimulated splenocytes were lower $(P<0.05)$ in mice immunized with cocktails 1,2 , and 4, compared to control infected mice (data not shown). Infection with MAP with or without immunization resulted in significant $(P<0.05)$ increases in serum $\operatorname{IgG}_{1}$ and $\operatorname{IgG}_{2 \mathrm{a}}$ compared to control noninfected mice (Fig. 4). Mice immunized with either $74 \mathrm{~F}$ or the MAP protein cocktails demonstrated increased $(P<0.05)$ MAP-specific serum IgG $\operatorname{Ig}_{2 \mathrm{a}}$ following challenge compared to control infected mice. In contrast, differences due to vaccination were not noted for MAP-specific serum $\operatorname{IgG}_{1}$ antibodies with similar levels noted for all infected mice regardless of vaccination when compared to control infected mice.

\subsection{Tissue culture}

Immunization with cocktails 1-4 did not significantly impact tissue colonization in the spleen after challenge with live MAP, yet there was a trend toward reduced MAP colonization noted in the cocktail 1 group compared to the control infected group (Fig. 5A). Similar reductions in MAP colonization were also noted in the MLN of mice receiving cocktails 1 and 2 prior to challenge, although these differences did not achieve statistical significance (Fig. 5C). However, liver colonization was reduced $(P<0.05)$ in mice immunized with cocktails 1 and 3 , as well as the $74 \mathrm{~F}$ polyprotein that served as a positive control in the study (Fig. $5 \mathrm{~B}$ ). Further, all protein cocktails significantly $(P<0.05)$ reduced MAP colonization in the ileum compared to infected controls (Fig. 5D). Although immunization with the combination of proteins in cocktail 4 (MAP1204, MAP1272c, and MAP2077c) provided less protection against MAP colonization compared to the 3 other cocktails, it was still effective in reducing tissue burden in the ileum.

\section{Discussion}

The four MAP protein candidates were chosen based upon earlier work suggesting moderate to high antigenic responses in serologic assays. Functions of these proteins include a peptide transport system permease protein, MAP1087; putative invasion proteins, MAP1204 and MAP1272c; and a STAS domain containing protein, MAP 2077c. Two of the 4 selected proteins (MAP1087 and MAP1204) had previously demonstrated strong reactivity with sera from naturally infected cattle in the subclinical stage of infection [16]. In addition, MAP1087, MAP1204, and MAP2077c all reacted with sera from experimentally infected calves in the early stage of infection [16]. The selection of these proteins was not based upon 

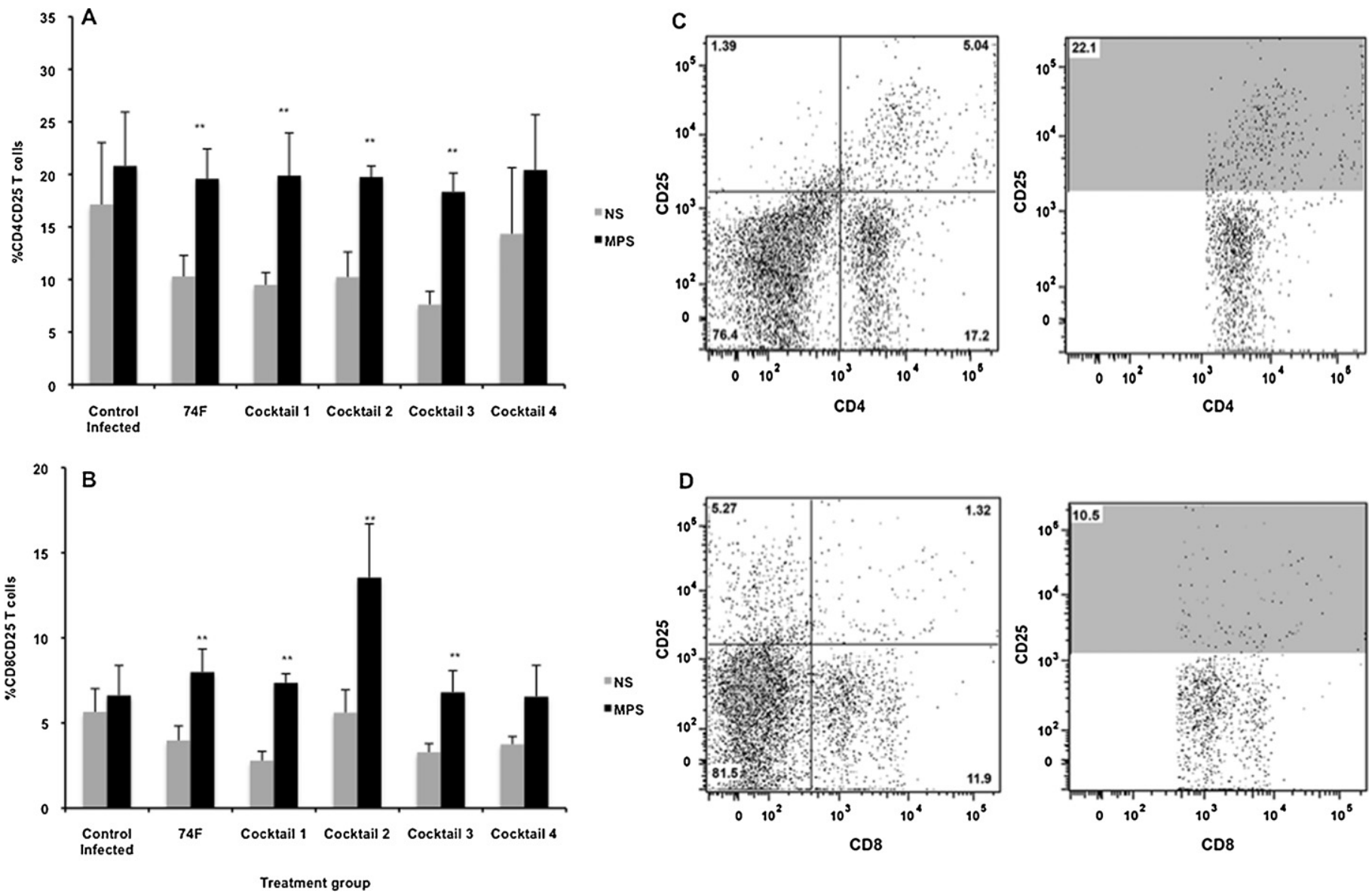

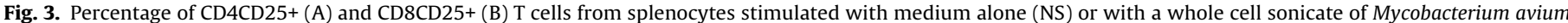

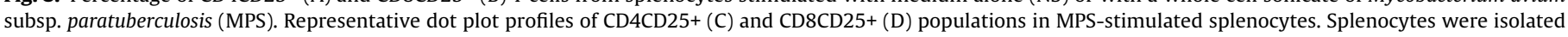

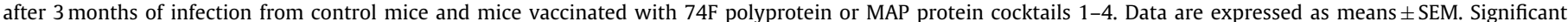
differences between NS and MPS stimulants within a treatment group are represented by asterisks $\left({ }^{* *} P<0.01 ;{ }^{*} P<0.05\right)$.

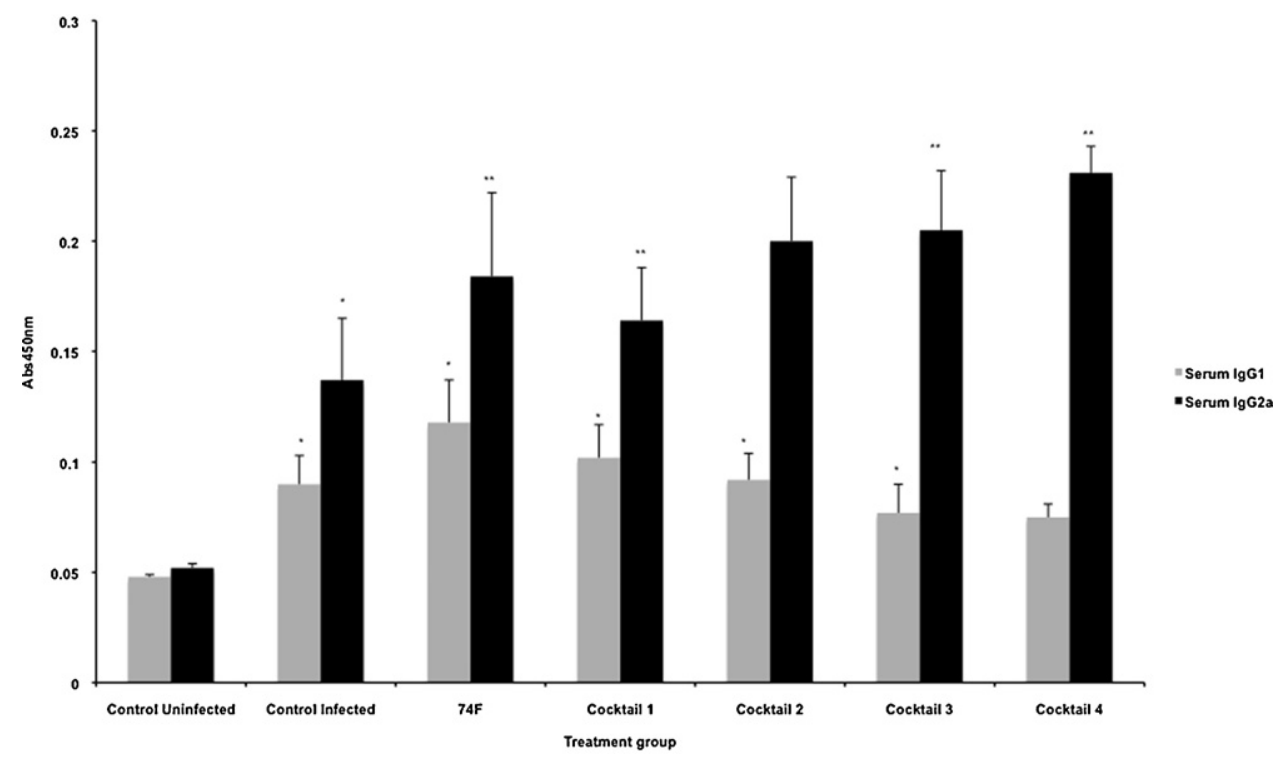

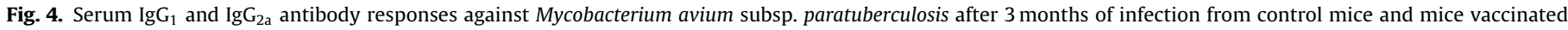

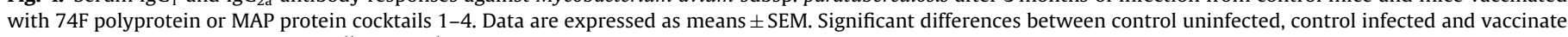
groups are represented by asterisks $\left({ }^{* *} P<0.01 ;{ }^{*} P<0.05\right)$. 

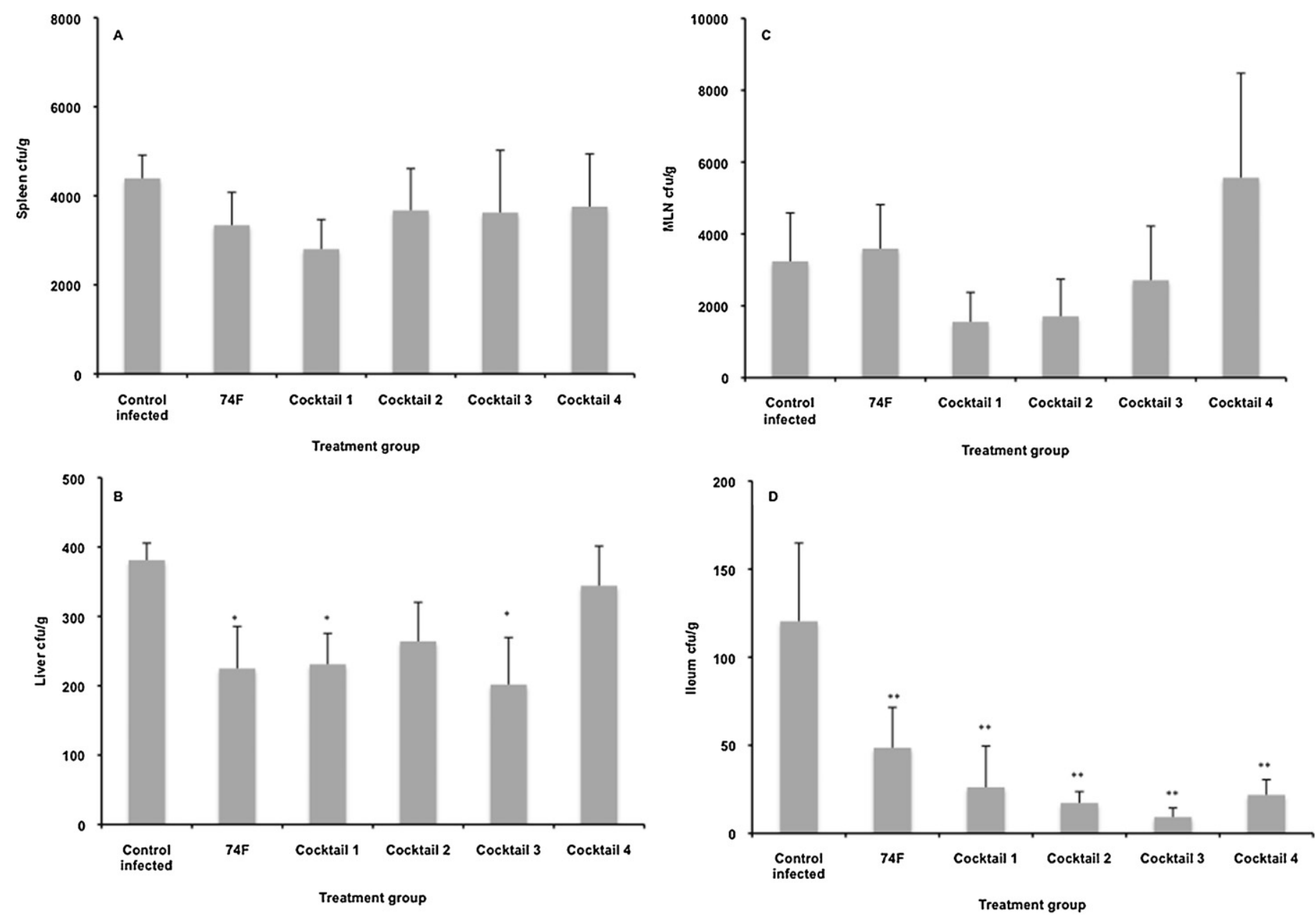

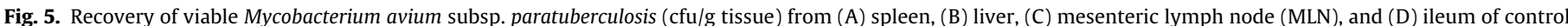

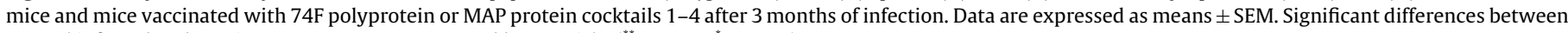
control infected and vaccinate groups are represented by asterisks $\left({ }^{* *} P<0.01 ;{ }^{*} P<0.05\right)$.

specificity to MAP and protein sequence analysis demonstrated significant alignment of all 4 proteins to both MAP and Mycobacterium avium. This is not surprising given the high level of genetic homology ( $>98 \%$ ) between MAP and $M$. avium, with few unique genes identified for MAP and even fewer immunogens [14,17]. Although partial sequences of MAP1204 were also found in other mycobacterial species, including $M$. bovis, this would not be a major detractor from potential use as a vaccine candidate. Sero-diagnostic tests for the detection of $M$. bovis infection using antigens such as ESAT-6, CFP-10, and MPB83, have demonstrated a lack of cross-reactivity in calves vaccinated with the whole-cell vaccine for MAP [13]. In addition, IFN- $\gamma$ responses to ESAT-6:CFP-10 antigens were observed to be highly specific for calves infected with $M$. bovis, with negligible reactivity noted for MAP- and M. avium-infected calves [18] or for calves vaccinated with a whole cell vaccine [13]. This would suggest that adequate tools are available to distinguish between MAP vaccinates and animals infected with $M$. bovis.

Although it is unknown how well immunogenic proteins translate into successful vaccines, it is understood that proteins can be highly antigenic, eliciting both humoral and cell-mediated immune responses. Many researchers utilize immune reactivity in the host as their primary method to screen protein candidates for subunit vaccines, with the hypothesis that an induced response is suggestive of protective immunity. Although proteomic and genomic screening approaches can be used to identify vaccine candidates, these tools are only useful if the candidates are recognized by the host immune system. Screening tools such as Western blotting have been effective for many bacterial pathogens, however, for intracellular pathogens such as MAP, antigen screening should include some measure of responsiveness in a cell-mediated assay since protection is aligned with Th1-mediated immunity in the host [19]. The proteins in the present study were selected upon observation of robust IFN- $\gamma$ responses in naturally infected cattle, combined with the ability to discriminate between infected and noninfected cattle with some measure of specificity.

Numerous infection models have been developed for MAP, with emphasis on ruminant species such as cattle, sheep, goats, deer, and bison [20] since these are the target species for paratuberculosis. However, the protracted period of subclinical infection that occurs in naturally infected hosts is mimicked in experimentally infected animals, resulting in lengthy study periods [20,21]. Mouse models provide a reasonable approach to efficiently evaluate vaccine candidates due to a shorter infection periods compared to ruminants, greater reproducibility due to more precise genetics amongst treatment animals, and reduced costs for care and housing, allowing for greater numbers of animals per treatment group. Mouse models for MAP infection have been adequately characterized and IP infection of Balb/c mice results in effective colonization of the major target tissues [22].

Th1-mediated immune responses may be indicative of exposure to mycobacterial pathogens, including MAP, but also appear to be essential to keep infection from progressing from 
subclinical to clinical disease. In a neonatal calf infection model, we were able to demonstrate the upregulation of immune markers including, robust antigen-specific IFN- $\gamma$ responses as well as induction of antigen-specific CD25, CD26, and CD45RO expression less than 3 months after infection [23]. Although Th2 responses are not known to be protective in the host, both Th1- and Th2-mediated immunity has been induced after vaccination with a whole cell preparation of MAP [24-26]. Recent studies have also demonstrated that MAP vaccines comprised of single proteins or protein complexes will also evoke strong Th1 responses [7-9,26-28]. In the present study, immunization of mice with MAP protein cocktails prior to challenge with live MAP resulted in similar induction of antigen-specific IFN- $\gamma$ when compared to control infected mice, although some attenuation of the IFN- $\gamma$ response was noted. Differences in IFN- $\gamma$ secretion between NS and MPS-stimulated cultures were lower for mice vaccinated with protein cocktails, particularly cocktail 1 . This would suggest that immunization with this triad of proteins may have resulted in greater constitutive secretion of IFN- $\gamma$ but lower antigen-specific IFN- $\gamma$ secretion after challenge, an effect that may be advantageous to the host. Pro-inflammatory effects of IFN- $\gamma$ can be both beneficial and detrimental to the host and a finite balance must be achieved in order to maintain effective immunity [28]. Interleukin-23 was upregulated by MAP infection, with increased secretion noted after stimulation with MPS antigen in vitro for all treatment groups. This is the first report describing effects of MAP infection on the secretion of IL-23. IL-23 is a newly recognized cytokine that is involved in the inflammatory response to mycobacterial infections, although little is known about its role in the immunopathology of MAP infections. IL-23 is required for the generation of effector memory $T$ cells and is also needed for generation of IL-17-producing T cells, which play an important role in the inflammatory response [29].

Although Th2-mediated cytokine production was not markedly different due to vaccination, an interesting observation was the pattern of IL-4 secretion noted between NS and MPS-stimulated splenocytes in mice vaccinated with MAP protein cocktails, particularly for mice immunized with cocktail 1. Vaccination with MAP proteins 1087,1204 , and 1272 c, in cocktail 1 resulted in higher constitutive secretion of IL-4 compared to the other treatment groups, something that was not apparent upon further exposure of splenocytes to MAP antigen in vitro. These results would suggest that this cocktail of MAP proteins modulated Th2 responses of the host after infection, an important consideration for selection of vaccine candidates. This is further substantiated by the increase in MAP-specific serum $\operatorname{IgG}_{2 \mathrm{a}}$ noted for mice immunized with either $74 \mathrm{~F}$ or MAP protein cocktails. Secretion of $\operatorname{IgG}_{2 a}$ antibodies is most closely associated with Th1-mediated immunity and cytokines such as IFN- $\gamma$, IL-4, and IL-10 can influence the isotype switch to $\operatorname{IgG}_{2 a}$ [30].

Immune responses to vaccination are critical for the control of infection in the host. Immunization with the MAP protein cocktails effectively reduced MAP colonization of the liver and ileum. In particular, cocktail 1 also demonstrated efficacy for reduced colonization of the spleen and mesenteric lymph node, providing the most consistent effect on retardation of infection in the host. Reduced colonization of tissues is a beneficial characteristic for paratuberculosis vaccines and has been reported for commercial vaccines such as Mycopar and Gudair, as well as for more recently developed subunit vaccines [7,9,31,32]. Decreased tissue burdens result in reduced shedding of MAP in the feces thereby allaying spread of infection within a herd [1]. Similar reductions in tissue burden have been reported for mice immunized with the $74 \mathrm{~F}$ polyprotein, with reduced recoveries of viable MAP from spleen, liver and mesenteric lymph nodes at 12 and 16 weeks postchallenge [8]. The highly positive results achieved with the 74F polyprotein prompted us to incorporate it into our study as a positive control. The Mycopar vaccine was an undesirable choice as a positive control vaccine in the current study as effects have not been previously evaluated in a mouse model. In addition, the Mycopar vaccine typically causes large granulomatous nodules at the injection site in ruminants, an effect that would not be handled well in a young mouse [31]. In ruminants, this local inflammatory effect is managed somewhat by injecting the vaccine in the fatty area of the brisket. Much of the benefit previously noted for the $74 \mathrm{~F}$ immunogen was repeated in the present study, with concurrent reductions in tissue colonization and activation of T cells as previously described. Despite this, cocktail 1 seemed to invoke the most consistent responses in protection against tissue colonization. Further, this triad of MAP proteins, 1087, 1204, and 1272c, appeared to more tightly regulate the immune response post-immunization both before and after challenge with live MAP. Host responses after immunization with either cocktail 2 or 3 more closely aligned themselves to results observed for cocktail 1 . The common protein between these 3 cocktails was MAP1087, whose known function is a peptide transport system permease protein. This type of transport protein has been considered as a potential vaccine for a wide variety of bacterial species [33]. This provides us with an interesting set of proteins to further evaluate as a potential MAP vaccine in a ruminant model.

In summary, the present study evaluated cocktails of MAP proteins as potential subunit vaccines for paratuberculosis. Cocktails of MAP proteins proved effective in protection against tissue colonization and invoked cell-mediated and humoral immunity in the host. Further evaluation of the components of cocktail 1, (MAP proteins 1087,1204 , and 1272c), needs to be undertaken to evaluate the potential of these proteins as subunit vaccines against Johne's disease.

\section{Conflict of interest}

The authors, J.R. Stabel and J.P. Bannantine, are employees of USDA-ARS, and USDA-ARS has filed a patent application for this work.

\section{Acknowledgments}

The authors would like to thank Janis Hansen and Margaret Walker for their technical expertise. We would also like to thank Bruce Pesch for the flow cytometric analyses.

\section{References}

[1] Kalis CH, Hesselink JW, Barkema HW, Collins MT. Use of long-term vaccination with a killed vaccine to prevent fecal shedding of Mycobacterium avium subsp. paratuberculosis in dairy herds. Am J Vet Res 2001;62:270-4.

[2] Begg DJ, Griffin JF. Vaccination of sheep against $M$. paratuberculosis: immune parameters and protective efficacy. Vaccine 2005;23:4999-5008.

[3] Juste RA, Alonso-Hearn M, Molina E, Geijo M, Vazquez P, Sevilla IA, et al. Significant reduction in bacterial shedding and improvement in milk production in dairy farms after the use of a new inactivated paratuberculosis vaccine in a field trial. BMC Res Notes 2009;2:233-9.

[4] Köhler H, Gyra H, Zimmer K, Dräger KG, Burkert B, Lemser B, et al. Immune reactions in cattle after immunization with a Mycobacterium paratuberculosis vaccine and implications for the diagnosis of M. paratuberculosis and M. bovis infections. J Vet Med B 2001;48:185-95.

[5] Muskens J, van Zijderveld F, Eger A, Bakker D. Evaluation of the long-term immune response in cattle after vaccination against paratuberculosis in two Dutch dairy herds. Vet Microbiol 2002;86:269-78.

[6] Nedrow AJ, Gavalchin J, Smith MC, Stehman SM, Maul JK, McDonough SP, et al. Antibody and skin-test responses of sheep vaccinated against Johne's disease. Vet Immunol Immunopathol 2007;116:109-12.

[7] Koets A, Hoek A, Langelaar M, Overkijk M, Santema W, Franken P, et al. Mycobacterial $70 \mathrm{kD}$ heat-shock protein is an effective subunit vaccine against bovine paratuberculosis. Vaccine 2006;24:2550-9.

[8] Chen LH, Kathaperumal K, Huang CJ, McDonough SP, Stehman S, Akey B, et al. Immune responses in mice to Mycobacterium avium subsp. paratuberculosis following vaccination with a novel $74 \mathrm{~F}$ recombinant polyprotein. Vaccine 2008;26:1253-62. 
[9] Kathaperumal K, Park SU, McDonough S, Stehman S, Akey B, Huntley J, et al Vaccination with recombinant Mycobacterium avium subsp. paratuberculosis proteins induces differential immune responses and protects calves against infection by oral challenge. Vaccine 2008;26:1652-63.

[10] Santema W, Hensen S, Rutten V, Koets A. Heat shock protein 70 subunit vaccination against bovine paratuberculosis does not interfere with current immunodiagnostic assays for bovine tuberculosis. Vaccine 2009;27:2312-9.

[11] Spickler AR, Roth JA. Adjuvants in veterinary vaccines: modes of action and adverse effects. J Vet Intern Med 2003;17:273-81

[12] Stabel JR. An improved method for cultivation of Mycobacterium paratuberculosis from bovine fecal samples and comparison to three other methods. J Vet Diagn Invest 1997;9:375-80.

[13] Stabel JR, Waters WR, Bannantine JP, Lyashchenko K. Mediation of host immune responses after immunization of neonatal calves with a heat-killed Mycobacterium avium subsp. paratuberculosis vaccine. Clin Vaccine Immunol 2011:2079-89.

[14] Bannantine JP, Paustian ML. Identification of diagnostic proteins in Mycobacterium avium subspecies paratuberculosis by a whole genome analysis approach. Methods Mol Biol 2006;345:185-96.

[15] Huntley JF, Stabel JR, Paustian ML, Reinhardt TA, Bannantine JP. Expression library immunization confers protection against Mycobacterium avium subsp. paratuberculosis infection. Infect Immun 2005;73: 6877-84

[16] Bannantine JP, Bayles DO, Waters WR, Palmer MV, Stabel JR, Paustian ML. Early antibody response against Mycobacterium avium subspecies paratuberculosis antigens in subclinical cattle. Proteome Sci 2008;6:5-16.

[17] Bannantine JP, Waters WR, Stabel JR, Palmer MV, Li L, Kapur V, et al. Development and use of a partial Mycobacterium avium subspecies paratuberculosis protein array. Proteomics 2008;8:463-74.

[18] Waters WR, Nonnecke BJ, Palmer MV, Robbe-Austerman S, Bannantine JP, Stabel JR, et al. Use of recombinant ESAT-6:CFP-10 fusion protein for differentiation of infections of cattle by Mycobacterium bovis and by M. avium subsp. avium and M. avium subsp. paratuberculosis. Clin Diagn Lab Immunol 2004; 11:729-35.

[19] Stabel JR. Immunology of paratuberculosis infection and disease. In: Behr MA, Collins DM, editors. Paratuberculosis: organism, disease, control. Cambridge, MA: CAB International; 2010. p. 230-43.

[20] Hines 2nd ME, Stabel JR, Sweeney RW, Griffin F, Talaat AM, Bakker $\mathrm{D}$, et al. Experimental challenge models for Johne's disease: a review and proposed international guidelines. Vet Microbiol 2007;122: 197-222.
[21] Begg DJ, Whittington RJ. Experimental animal infection models for Johne's disease, an infectious enteropathy caused by Mycobacterium avium subsp. paratuberculosis. Vet J 2008;176:129-45.

[22] Talaat AM. Experimental small animal models of paratuberculosis. In: Behr MA Collins DM, editors. Paratuberculosis: organism, disease, control. Cambridge, MA: CAB International; 2010. p. 223-7.

[23] Stabel JR, Robbe-Austerman S. Early immune markers associated with Mycobac terium avium subsp. paratuberculosis infection in a neonatal calf model. Clin Vaccine Immunol 2011;18:393-405.

[24] Gillan S, Hughes AD, O'Brien R, Griffin FT. Ovine immune parameters following immunization against Mycobacterium avium ssp. paratuberculosis using a lipidbased live-cell vaccine. Vet Immunol Immunopathol 2010:109-19.

[25] Platt R, Thoen CO, Stalberger RJ, Chiang Y, Roth JA. Evaluation of the cell-mediated immune response to reduced doses of Mycobacterium avium ssp. paratuberculosis vaccine in cattle. Vet Immunol Immunopathol 2010: 122-6.

[26] Kathaperumal K, Kumanan V, McDonough S, Chen LH, Park SU, Moreira MA, et al. Evaluation of immune responses and protective efficacy in a goat model following immunization with a cocktail of recombinant antigens and a polyprotein of Mycobacterium avium subsp. paratuberculosis. Vaccine 2009;27: 123-35.

[27] Nguyen TK, Wieland W, Santema W, Hoeboer J, van Eden W, Rutten V, et al. Immune response of cattle immunized with a conjugate of the glycolipid glucose monomycolate and protein. Vet Immunol Immunopathol 2011;142:265-70.

[28] Schroder K, Hertzog PJ, Ravasi T, Hume DA. Interferon-gamma: an overview of signals, mechanisms, and functions. J Leuko Biol 2004;75:163-9.

[29] Khader SA, Cooper AM. IL-23 and IL-17 in tuberculosis. Cytokine 2008;41:79-83.

[30] Stevens TL, Bossie A, Sanders VM, Fernandez-Botran R, Coffman RL, Mosmann TR, et al. Regulation of antibody isotype secretion by subsets of antigen-specific helper T cells. Nature 1998;334:255-8.

[31] Patton EA. Paratuberculosis vaccination. Vet Clin North Am Food Anim Pract 2011;27:573-80.

[32] Reddacliff L, Eppleston J, Windsor P, Whittington R, Jones S. Efficacy of a killed vaccine for the control of paratuberculosis in Australian sheep flocks. Vet Micro 2006;115:77-90.

[33] Garmory HS, Titball RW. ATP-binding cassette transporters are the targets for the development of antibacterial vaccines and therapies. Infect Immun 2004;72:6757-63. 